\title{
A performance analysis of participating life insurance contracts
}

\author{
Roger Faust • Hato Schmeiser • Alexandra Zemp
}

Published online: 24 November 2011

(C) Springer-Verlag 2011

\begin{abstract}
Traditional life insurance products, in particular participating life insurance contracts, are often criticized. Their performance is often said to be poor compared to other investment alternatives. Interestingly, this perception appears to persist although very little research has been conducted into the performance of participating life insurance contracts. But are participating life insurance contracts actually bad for policyholders? We conduct a performance analysis based on contracts offered in the German market, in order to provide evidence to support decision making by policyholders.
\end{abstract}

Zusammenfassung Traditionelle Lebensversicherungsprodukte wie die gemischte Kapitallebensversicherungen werden seit Jahren immer wieder kritisiert. Zu nennen ist zum Beispiel der Hamburger Ampelcheck, welcher die gemischte Kapitallebensversicherung als nicht geeignet für die Altersvorsorge ansieht. Doch wie gut oder schlecht ist dieses Versicherungsprodukt wirklich für die Versicherungsnehmer? Die Forschung in diesem Bereich ist limitiert. Deshalb führen wir eine umfassende Performanceanalyse von der gemischten Kapitallebensversicherung durch, um privaten Investoren eine Entscheidungshilfe zur Verfügung zu stellen.

This article summarizes main findings of the paper "A Performance Analysis of Participating Life Insurance Contracts" by Faust et al. (2010) as it was presented at the annual meeting of the German Association for Insurance Science in Berlin in March 2011. Details regarding methodology and detailed results can be found in the original paper.

R. Faust $\cdot$ H. Schmeiser $(\bowtie) \cdot$ A. Zemp

Institute of Insurance Economics, University of St. Gallen, Kirchlistrasse 2, 9010 St. Gallen,

Switzerland

e-mail: hato.schmeiser@unisg.ch 


\section{Introduction}

As a consequence of the financial crisis, private investors currently seek for safe investments with low downside risk. In this context, minimum interest rate guarantees embedded in financial products are one option for investors. Insurance companies offer investment products with such a downside protection and are often perceived as safe harbor. ${ }^{1}$ The participating life insurance (PLI hereafter) is one of the most important products in the life insurance sector with a built in minimum interest rate guarantee. In most European countries, these contracts are typically characterized by an embedded term life insurance, a cliquet-style interest rate guarantee, ${ }^{2}$ and bonus participation rules with regard to the insurer's reserve situation (surplus fund). However, administrative costs and complex profit distribution schemes between policyholders and shareholders make it difficult to measure the performance of this product from the policyholder's point of view.

The characteristics of PLI contracts make it difficult to measure their performance. A PLI embeds various (explicit and implicit) options as well as complex bonus distribution schemes between policyholders and shareholders. In addition, an insurance company's management has a certain discretion with respect to some parameters. Furthermore, wealth transfers between different groups of policyholders take place. In order to get over these difficulties, we measure the performance of PLI contracts from an ex ante perspective while taking embedded options, bonus distribution, and management's discretion into account. We empirically calibrate our model with market data and simulate various insurance collectives to incorporate wealth transfer effects.

In order to get a clear picture of the performance of PLI, we decompose PLI in a term life insurance and an investment part and simulate the cash flow distribution of the investment part under the real world measure $\mathbb{P}$. Further, we create two benchmark portfolios based on the same underlying to measure the impact of the interest rate guarantee and the bonus distribution rules on the cash flows of the portfolio. By calibrating our model with empirical market data, we are able to show in which cases the interest rate guarantee and the mechanisms applied by the insurance company can be beneficial to the policyholder. In addition, we show how the payoff distribution depends on the initial reserve situation and management's discretion. We do not benchmark the PLI using a fair (risk-neutral) pricing approach, which would mean to compare the observed market price with the calculated fair price, because we believe that the underlying assumption of perfect and frictionless markets is rather not fulfilled in this context. We doubt that instruments exist that enable policyholders to replicate the PLI's cash flows. We think that consumers will rather judge products depending on personal preferences and actually available alternatives.

\footnotetext{
${ }^{1}$ For example, in the German life insurance market, the estimated increase in premium income in 2009 is 4.8 percent compared to $0.8 \%$ in 2008 (see GDV, 2009, Beitragseinnahmen der Versicherungswirtschaft, accessed January, 2010 at http://www.gdv.de/Downloads/Pressemeldungen_2009/ Tabellenanhang_PM_2009.pdf). This increase might be mainly attributable to an increased risk aversion and/or risk awareness following the financial crisis.

${ }^{2}$ In case of a cliquet-style interest rate guarantee, the guaranteed rate of interest has to be credited to the policyholders' account on a year-to-year basis.
} 
The contribution is that we neither rely on a single performance measurement ratio nor do we provide an ex post analysis. Instead, the introduced framework allows a comparison of the complete payoff distribution on an ex ante basis. This general approach is subsequently not bonded to one specific subjective preference scheme. Further, we model an insurance company with various insurance collectives in order to incorporate wealth transfer effects between different groups of policyholders. Only Hansen and Miltersen (2002) analyzed participating life insurance contracts with pooled accounts before, but just for a two-policyholders case.

\section{Model framework}

Here, we briefly explain the model framework. For a detailed description including all relevant formulas, refer to the original paper by Faust et al. (2010). First, we illustrate an insurance company which has only one single insurance contract. In Sect. 2.5, the mechanism introduced for the single contract company is applied to an insurer with more than one contract.

\subsection{Basic model framework}

Our model builds on PLI contracts offered in Germany, but could be easily applied to similar regulatory frameworks (e.g., Switzerland or Austria). The policyholder pays a constant annual premium at the beginning of each year given no previous termination of the contract by death or surrender. The insurance company uses a certain amount of the annual premium to cover its costs. Costs are divided into annual operational costs and acquisition costs. The latter are allocated over the first five years of the contract. Another part of the premium is needed to cover the term life insurance. The remaining amount of the annual premium is invested in an asset portfolio. This savings part of the premium features an annual minimum interest rate and builds up the policyholder's savings account.

To calculate the annual premium for the term life insurance contract, we use actuarial fair premiums and market loadings. To account for a decreasing sum insured (also referred to as net amount at risk), the term life insurance premium is annually adjusted so that the sum insured equals the guaranteed death benefit minus the accumulated savings account. Thereby, the guaranteed death benefit equals the guaranteed terminal payment as common in most PLI contracts.

The investment in the investment alternatives equals the annual premium minus the premium for the term life insurance contract. In addition, front-end loads as a proportion of assets invested are subtracted. In order to incorporate management and administrative fees associated with these benchmark portfolios, an annual fee (defined as a percentage of the total assets) is deducted at the end of each year. Thus, it becomes clear that the benchmark portfolios have another cost structure than the PLI. While costs regarding the PLI contract are charged in absolute values in terms of annual operational costs and acquisition costs, the benchmark portfolios involve front-end loads and annual fees in percent. 
Table 1 Balance sheet of a simulated insurance company

\begin{tabular}{ll}
\hline Assets (market values) & Liabilities (market values) \\
\hline$A_{r}:$ assets attributable to & $A_{f}:$ surplus fund \\
policyholders (either on an & $A_{g}:$ policyholders' savings accounts (subject to minimum interest \\
individual or collective basis) & rate guarantee) \\
& $A_{d p}:$ policyholders' distributed profits accounts \\
& $A_{d t b}:$ policyholders' distributed terminal bonus accounts \\
\hline
\end{tabular}

Because we are interested in the investment result of the PLI and not in the effect of the term life insurance, we analyze only the savings parts of both premiums. We assume that the investor wants to buy a term life insurance contract in both alternatives and hence, this part of the contract does not influence his decision.

\subsection{Portfolio development}

We illustrate a simplified balance sheet of an insurance company with market value accounting in Table 1 . The liability side of this balance sheet can be divided into two different parts, the policyholders' accounts, $A_{g}, A_{d p}$, and $A_{d t b}$, as well as the surplus fund $A_{f}$. While the policyholders' accounts are attributable to policyholders on an individual basis, the surplus fund is attributable to all policyholders as a group. Although the single contract company has only one policyholder, the surplus fund is still different from the policyholders' accounts: The surplus fund has the function of a risk buffer. That is to say it is built up in times of high returns on the asset portfolio and reduced in times of low returns. Grosen and Jørgensen (2000) work with a similar account, the so-called bonus reserve, which is determined by the difference between book and market values.

We assume that the insurance company invests in a diversified portfolio of stocks and bonds. In our model, the return on this asset portfolio is first used to cover this interest rate guarantee. If the achieved return is insufficient to cover the guarantee, additional capital will be required to cover the interest rate guarantee. We assume that the insurance company is always able to cover this required amount of capital by equity capital. If the PLI's earnings on assets are positive after covering the interest rate guarantee, the remaining profit is distributed to the surplus fund $A_{f}$, to shareholders in form of dividends, and to the insurer's equity capital (retentions of earnings).

On the contrary, the benchmark portfolios do not involve any interest rate guarantee or bonus distribution scheme.

\subsection{Bonus distribution}

In participating policies, the insurance company is obligated to give policyholders a share in profits. The surplus fund $A_{f}$ provides an intermediate mechanism which aims at stabilizing returns to policyholders over time. We introduce a decision rule based on the framework presented in Kling et al. (2007) in order to establish a bonus distribution mechanism in our model. 
The insurance company defines a certain target rate of interest which is planned to be granted to the policyholders' accounts annually in order to maintain returns for policyholders stable. This target rate of interest is given to the policyholders as long as the surplus fund quota $A_{f} / A_{g}$ stays within a defined range. In order to maintain returns to policyholders stable on a year-to-year basis whenever possible, the target rate of interest generally applies to all accounts which are attributable to policyholders on an individual basis even though the interest rate guarantee only applies to the savings account.

These profits are allocated between the policyholder's terminal bonus account $A_{d t b}$ and the policyholder's distributed profits account $A_{d p}$.

\subsection{Cash flows}

We distinguish between three possible events which lead to a payoff to the policyholder (or his heirs respectively). Namely, surrender of the policy before maturity, death before maturity, or survival until maturity.

In case of death, policyholders (or rather their heirs) receive the total amount on their accounts, i.e., their savings accounts, their distributed profits accounts, and their distributed terminal bonus accounts. In addition, policyholders' heirs would receive the sum insured of the term life insurance contract. However, since we are interested in the investment result of the PLI and not in the effect of the term life insurance, we do not include this cash flow in our subsequent analysis.

If a policyholder cancels his policy, he receives the amount on his savings account, on his distributed bonus account, and the fraction of his distributed terminal bonus account whereas a penalty is applied to the savings and the distributed bonus account.

Finally, if a policyholder continues the contract until maturity, the insurer pays the total amount of his different accounts. As we employ a discrete time model, death and cancellation in the last period are assumed to lead to equal payoffs at maturity.

Unlike the PLI contract, the benchmarks do not differentiate between death of the policyholder, surrender, and survival until maturity. Hence, the current value of the respective benchmark portfolio is paid out in all three possible events. Consequently, there is not any explicit surrender charge. However, there is an implicit surrender charge since front-end loads are distributed over less periods and, therefore, loads are higher in percent per year.

\subsection{Modeling the insurer's portfolio}

After introducing our model for a single contract insurance company, we apply it to an insurance company with more than one contract. We simulate a life insurance company's underwriting portfolio with various insurance collectives. The contract duration is the same for all collectives but the different collectives vary in their remaining time to maturity. Each insurance collective is homogeneous, i.e., contains policyholders of same age and mortality whose contracts have the same remaining time to maturity. The insurance company starts with one single insurance collective at point in time 0 . Then, every year a new collective is initiated.

The basic mechanisms introduced remain the same. However, there is only one surplus fund account $A_{f}$ for all contracts whereas the policyholders' accounts $\left(A_{g}\right.$, 
$A_{d p}$, and $A_{d t b}$ ) remain on an individual basis. One additional difference between the previously introduced single contract company and the various insurance collectives is that with more than one contract cash outflows occur every year based on how many members of each collective die or cancel their policy. ${ }^{3}$ If a policyholder surrenders, the amount on his savings, distributed profits, and terminal bonus account which is not paid out is distributed to the joint surplus fund $A_{f}$. Hence, policyholders profit from the cancellation of others.

We assume that mortality and surrender risk can be diversified away by the law of large numbers. That is to say, each insurance collective consists of so many individual policyholders, who die and surrender independently of each other, that a deterministic fraction of each collective dies and surrenders in each period based on the individual mortality tables and probabilities of cancellations (see also, e.g., Hansen and Miltersen 2002).

Our numerical analysis focuses on single contracts given the surplus fund in order to analyze payoffs obtained by individual policyholders.

\section{Numerical analysis}

\subsection{Model calibration}

We apply our model to contracts with a maturity of twelve years. We assume that policyholders start premium payments at the beginning of age 53 so that they would receive their survival benefit at the beginning of age 65 (retirement). We base our contract parameters on the actual offering of a German life insurance company. ${ }^{4}$ The policyholder pays an annual premium of $5000 €$ and has a guaranteed death benefit of $61491 €$. Acquisition costs of $1487.70 €$ are allocated over the first five years. Annual administrative costs are $202.97 €$.

We consider two benchmark portfolios: A mutual fund (MF) and an exchangetraded fund (ETF). Both are very common investment alternatives for private investors but involve different transaction costs. Thereby, the ETF benchmark is a kind of extreme case due to its low fees. We calculate fees for these benchmark portfolios based on fees reported by Khorana et al. (2007) for MFs sold in Germany and based on calculations provided by the Frankfurt Stock Exchange for ETFs. ${ }^{5}$

\subsection{Surplus fund}

Besides the function of stabilizing profits over time, the surplus fund is also an additional source of income for policyholders. If a policyholder enters an insurance company possessing a high amount of assets in the surplus fund, this policyholder

\footnotetext{
${ }^{3}$ In the single contract company, only one cash flow will occur after which the insurance company ceases to exist (as the single contract was paid out).

${ }^{4}$ We used a contract offered by the HUK Coburg (cf. www.huk.de). The information used for our simulation in respect to the contract calibration are publicly available.

${ }^{5}$ See http://www.boerse-frankfurt.de/DE/MediaLibrary/Document/Sonstiges/etf_handbuch.pdf.
} 


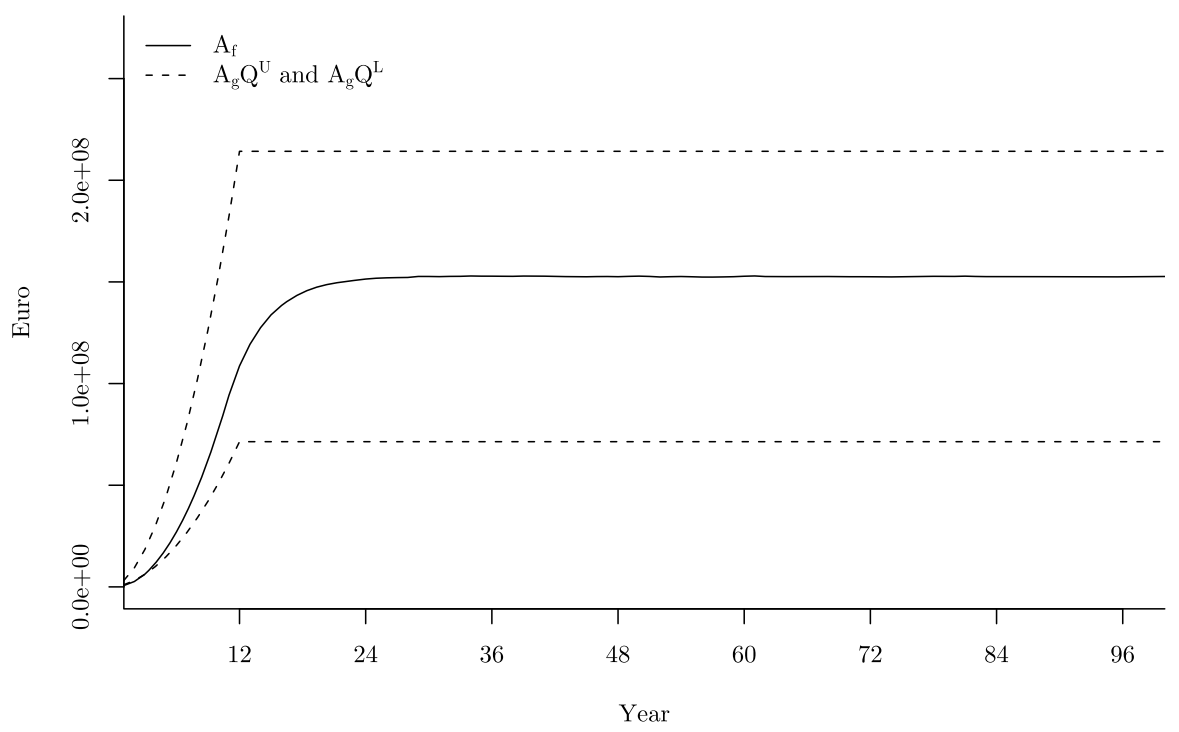

Fig. 1 Development of the expected surplus fund in the sample case. The dashed lines provide the lower and upper bounds in each year, which are constant once the 12th insurance collective has been set up

will profit from earnings of a surplus fund which was built up by others. On the other hand, if the policyholder enters a contract when the surplus fund is comparably low, he will tend to build it up whereof future policyholders will profit. Hence, there is a kind of cross-subsidization between policyholders. Thus, from a policyholder's perspective, the level of the surplus fund is crucial. However, individuals who enter a PLI contract do in general not know the level and whether the surplus fund is rather stable or not. ${ }^{6}$

Figure 1 shows how the surplus fund develops on average over time in our sample case. The dashed lines provide the lower and upper bounds in each year, which are constant in our setting once the 12th insurance collective has been set up. Based on the convergence behavior observable, we analyze contracts with three different starting points. Contract 1 starts at point in time 0 when the surplus fund is empty $\left(A_{f \text {,initiation }}=0\right)$. Contract 2 is established at the end of the 12 th year when 12 collectives exist and the surplus fund has partially been built up. At point in time 24, when the surplus fund is rather stable, contract 3 is initiated. Each contract (contract 1 , contract 2 , contract 3 ) refers to one single policyholder in the collective.

Costumers benefit if they enter when the surplus fund has already been built up (contract 3). Then they will (on average) earn returns on assets others paid for and do not have to pay for assets which others will benefit of. Certainly, it is less beneficial if

\footnotetext{
${ }^{6}$ In order to gather an indication of the current level of the surplus fund, policyholders could analyze the balance sheet of the insurance company. However, the balance sheet might only provide information on book values but not on the required market values. Hence, a policyholder would need a high level of financial literacy in order to be able to derive implications on the actual level of the surplus fund.
} 
policyholders still have to build up the surplus fund (contract 1, contract 2). However, entering the contract when the surplus fund is greater than zero (contract 2), the policyholders might still profit from this mechanism due to earnings provided by assets already in the surplus fund.

In order to clarify results with respect to the last period which accounts for more than $70 \%$ of all outcomes, we illustrate the payoff distributions (histograms) of the PLI contracts and the benchmark portfolios for period 12 in Fig. 2. The figure shows how peaked the PLIs' payoff distributions are compared to the MF and the ETF. The payoff distribution of the ETF is very similar to the one of the MF but is shifted to the right due to the lower transaction costs. Comparing contract 1 and 3 shows that the payoff distribution of contract 1 is shifted to the left with a lower upside potential.

\subsection{Management's discretion}

Our previous results have shown that the surplus fund has an important impact on the payoff distribution. However, we assumed parameters to be constant and differences with respect to the different contracts were caused by the initial level of the surplus fund. In what follows, we analyze the effects of management's discretion with regard to contract 3. We examine the effect on the PLI's payoff distribution if management changes the target rate of interest directly after the policyholder's first premium payment. We focus on an increase of the target rate from $r_{z}=3.5 \%$ to $r_{z}=4.0 \%$ and a decrease to $r_{z}=3.0 \%$.

Similar to Figs. 1, $3 \mathrm{a}$ and $3 \mathrm{~b}$ show how the surplus fund develops on average over time given the change of the target rate of interest in year 24 . The dashed lines provide the lower and upper bounds in each year, the dotted line displays the level of the surplus fund given no change in the target interest rate. If the target rate increases to $r_{z}=4.0 \%$, the surplus fund first decreases and then stabilizes at a lower level. On the contrary, with a decrease to $r_{z}=3.0 \%$, the surplus fund first increases and then stabilizes at a higher level. Figure $3 \mathrm{c}$ and $3 \mathrm{~d}$ show the payoff distribution in the last period (similar to Fig. 2). The dotted line denotes the density function given no target rate change. Both rate changes, $r_{z}=3.0 \%$ and $r_{z}=4.0 \%$, lead to a much less peaked payoff distribution compared to the contract without a change of the target rate. In addition, the rate change to $r_{z}=3.0 \%$ causes the payoff distribution to be more skewed than the change to $r_{z}=4.0 \%$.

\subsection{Performance measurement}

Next, a preference dependent valuation of the different investment opportunities is derived based on the payoff distributions shown. In order to do so, assumptions regarding the state and time preferences of the policyholder are needed. In this subsection, we assume that whenever payments take place before the end of maturity (because of surrender or death of the investor), the corresponding cash-flows are reinvested and compounded with the annual minimum interest rate. This yields one single cash flow distribution $L_{T}$ at time $T$ for each investment alternative.

The premiums paid into the different saving products (i.e., after detaching the term life insurance) are the same for all alternatives. Compounding the premium payments 


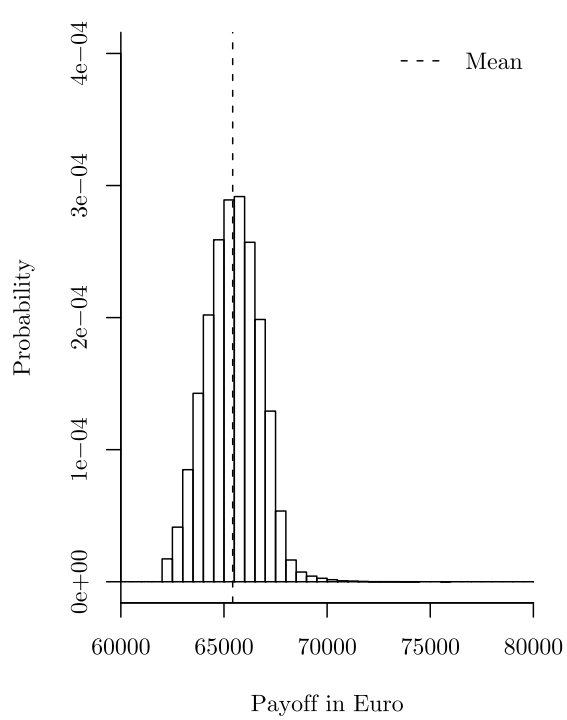

(a) PLI payoffs contract 1

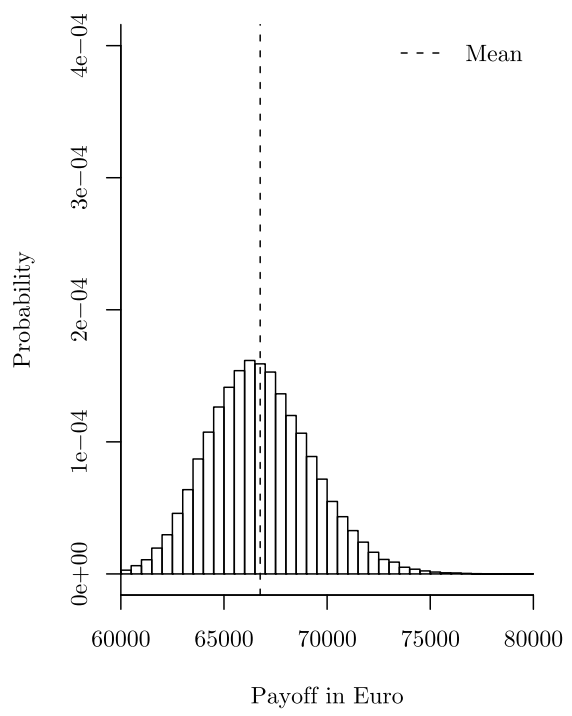

(c) MF payoffs

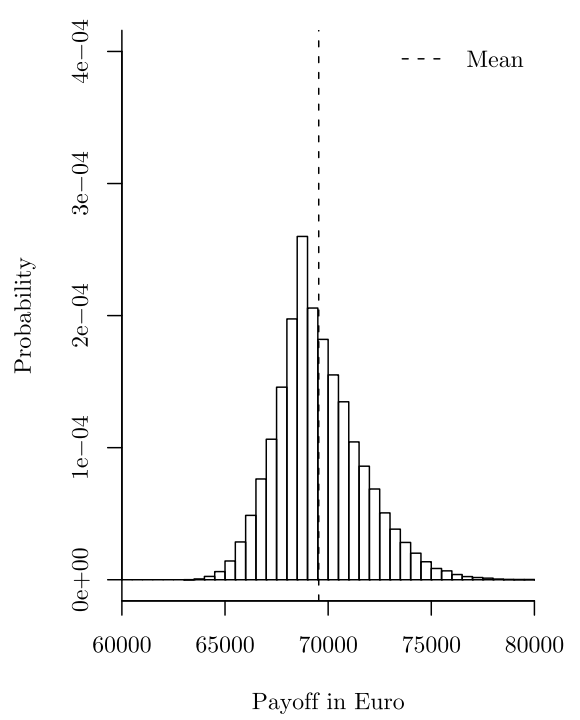

(b) PLI payoffs contract 3

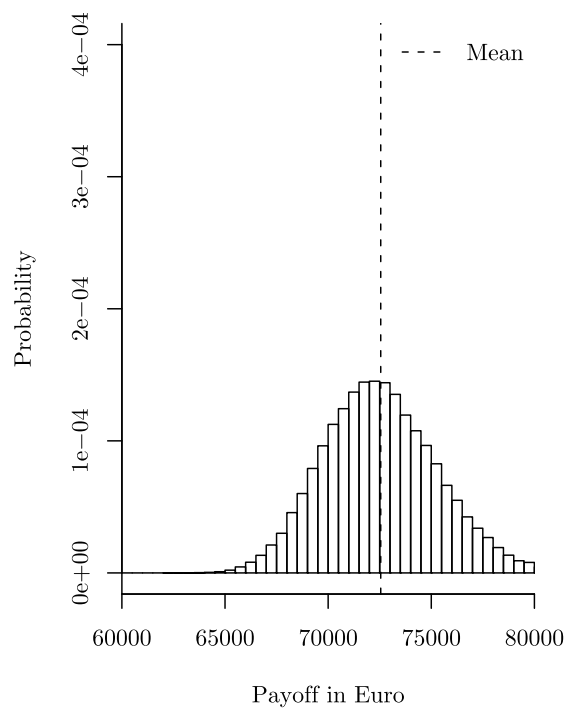

(d) ETF payoffs

Fig. 2 Histograms and mean of the payoff distributions conditional upon payout in the last year for each contract

with the interest rate, while taking surrender and survival probabilities of the policyholder into account, leads to a (deterministic) terminal value of premium payments of $Y_{T}=55518$. As it is done in Gatzert and Schmeiser (2009), we perform a comparison of the four different cases by using modified forms of three different classical 


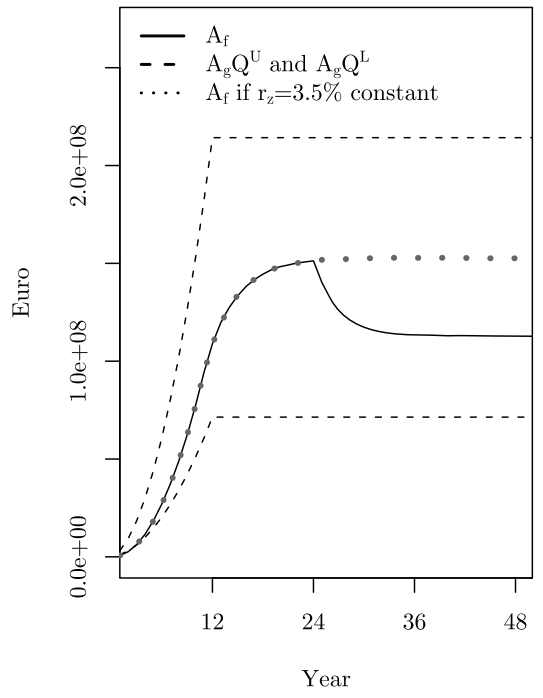

(a) Surplus fund for $r_{z}=4.0 \%$

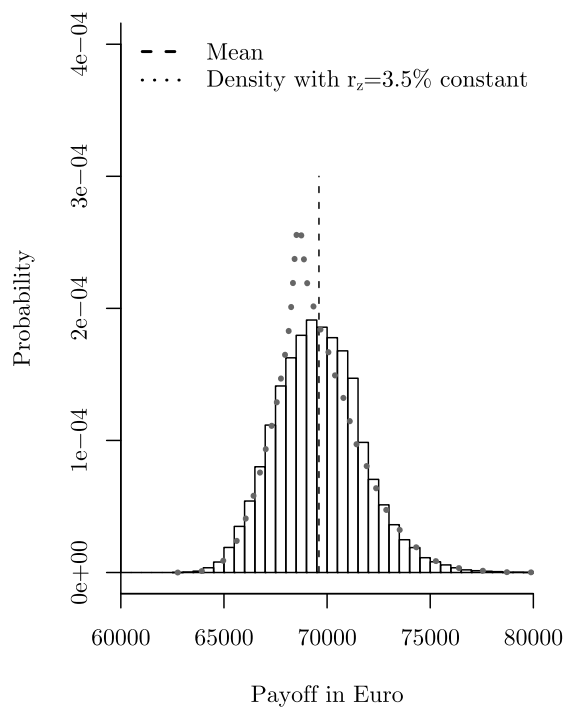

(c) Payoff distributions for $r_{z}=4.0 \%$

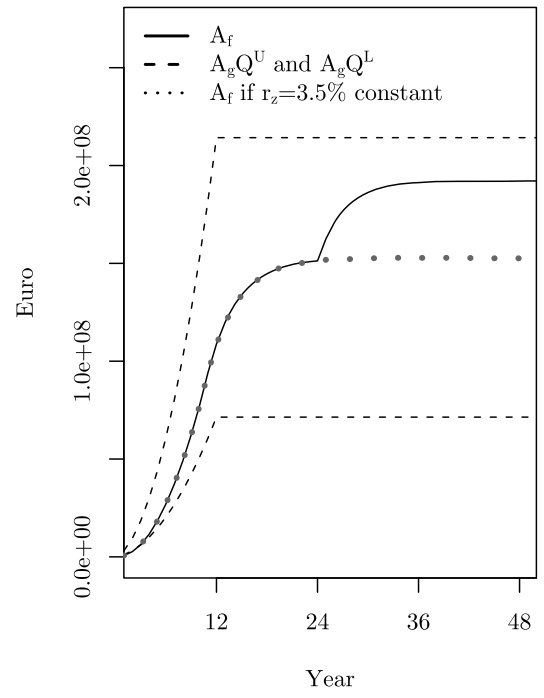

(b) Surplus fund for $r_{z}=3.0 \%$

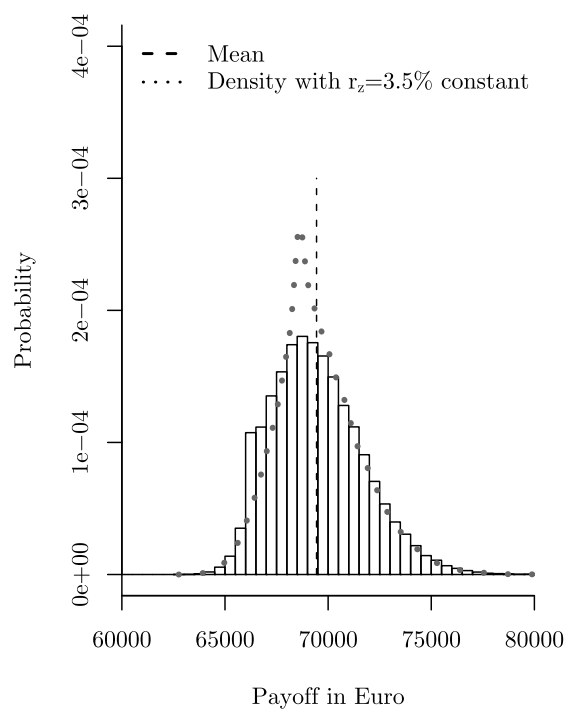

(d) Payoff distributions for $r_{z}=3.0 \%$

Fig. 3 Histograms and mean of the payoff distributions of contract 3 conditional upon payout in the last year given a change in the target rate of interest at the beginning of the contract's life. Panel (a) and (b) show the corresponding expected level of the surplus fund

performance measures. First, an adaption of the Sharpe ratio (see Sharpe 1966) can be defined in the following way:

$$
\text { Sharpe } \operatorname{ratio}\left(L_{T}\right)=\frac{E\left(L_{T}\right)-Y_{T}}{\sigma\left(L_{T}\right)}
$$


Table 2 Modified performance measures for the valuation of four different investment opportunities

\begin{tabular}{llll}
\hline Contract type & Sharpe ratio & Omega & Sortino ratio \\
\hline PLI Contract 1 & -0.057 & -0.133 & -0.063 \\
PLI Contract 3 & 0.109 & 0.286 & 0.133 \\
MF & 0.020 & 0.049 & 0.023 \\
ETF & 0.238 & 0.689 & 0.313 \\
\hline
\end{tabular}

For instance, in the case of the ETF benchmark portfolio, this will lead to

$$
\text { Sharpe } \operatorname{ratio}\left(L_{T}\right) \approx \frac{60536-55518}{21083} \approx 0.238
$$

Following Gatzert and Schmeiser (2009), a modified form of Omega and the Sortino ratio can be defined by (see Shadwick and Keating 2002; Sortino and van Der Meer 1991)

$$
\operatorname{Omega}\left(L_{T}\right)=\frac{E\left(L_{T}\right)-Y_{T}}{E\left(\max \left(Y_{T}-L_{T}, 0\right)\right)}
$$

and

$$
\text { Sortino } \operatorname{ratio}\left(L_{T}\right)=\frac{E\left(L_{T}\right)-Y_{T}}{\sqrt{E\left(\max \left(Y_{T}-L_{T}, 0\right)^{2}\right)}} .
$$

Table 2 provides an overview of the different performance ratios of the four investment opportunities in focus. The used performance measurements give a clear picture: The contract type ETF dominates all other investment forms analyzed. Performance ratios are best for the ETF portfolio and worst for PLI contract 1 as already indicated by our previous results. Further, PLI contract 3 dominates the MF benchmark and PLI contract 1, whereas contract 1 is dominated by all other alternatives. Hence, PLI contract 3 appears to be superior to the MF portfolio given our underlying assumptions about preferences.

To conclude, the ETF benchmark portfolio appears to be the best choice due to the low transaction costs. On the other hand, if the surplus fund is already built up, the PLI tends to perform better than the MF benchmark.

\section{Conclusion}

This article provides a summary of the paper of Faust et al. (2010) that was presented at the annual meeting of the German Association for Insurance Science in Berlin in March 2011.

We analyze the controversial question whether participating life insurance contracts are actually beneficial for policyholders. Even though this contract form is very common in insurance practice, only very little research has been conducted in respect to its performance. In a first step, a framework to estimate payoffs from participating life insurance contracts from the point of view of policyholders is developed. In order to do so, we decompose a participating life insurance contract into an investment part and a term life insurance. Hence, we are able to analyze the benefits of the minimum 
interest rate guarantee in combination with the profit distribution rules independent from the term life insurance. Thereby, we model more than one single contract which allows us to incorporate distribution effects between policyholders. In a second step, we simulate and benchmark the complete payoff distribution on an ex ante basis. We show how the payoff distribution depends on the level of the surplus fund at inception of the contract and analyze the effect of management's discretion.

To conclude, the paper shows that policyholders have very little chance to predetermine the cash flow distribution as long as the future behavior of management and the current level of the surplus fund are unknown or realistic assumption cannot be derived in this respect. Also, our preference dependent performance analysis shows that in most cases an ETF portfolio will assumedly perform better than each possible participating life insurance contract.

In order to get a better understanding of how the underlying capital market parameters influence the performance, future research could analyze a more detailed asset model (i.e., an interest rate model for the bond fraction of the asset portfolio) or derive sensitivities with regard to drift and volatility of stocks and bonds. In addition, longer contract periods may be analyzed.

\section{References}

Faust, R., Schmeiser, H., Zemp, A.: A performance analysis of participating life insurance contracts. Working Papers on Risk Management and Insurance 76 (2010)

Gatzert, N., Schmeiser, H.: Pricing and performance of mutual funds: lookback versus interest rate guarantees. J. Risk 11(4), 31-49 (2009)

Grosen, A., Jørgensen, P.L.: Fair valuation of life insurance liabilities: the impact of interest rate guarantees, surrender options, and bonus policies. Insur. Math. Econ. 26(1), 37-57 (2000)

Hansen, M., Miltersen, K.: Minimum rate of return guarantees: the Danish case. Scand. Actuar. J. 2002(4), 280-318 (2002)

Khorana, A., Servaes, H., Tufano, P.: Mutual fund fees around the world. Rev. Financ. Stud. 22(3), 12791310 (2007)

Kling, A., Richter, A., Ruß, J.: The interaction of guarantees, surplus distribution, and asset allocation in with-profit life insurance policies. Insur. Math. Econ. 40(3), 164-178 (2007)

Shadwick, W.F., Keating, C.: A universal performance measure. J. Perform. Meas. 6(3), 59-84 (2002)

Sharpe, W.F.: Mutual fund performance. J. Bus. 39(1), 119-138 (1966)

Sortino, F., van Der Meer, R.: Downside risk. J. Portf. Manag. 17(4), 27-31 (1991) 